Research Article

\title{
Shear Strength Prediction for SFRC Shear Wall with CFST Columns by Softened Strut and Tie Model
}

\author{
Peibo You $\mathbb{D D}^{1,2}$ Shuaiqi Song, ${ }^{1}$ Haiyang Zhang, ${ }^{3}$ Lijuan Zhang, ${ }^{4}$ Ke Shi, ${ }^{5}$ and Yi Wang ${ }^{1}$ \\ ${ }^{1}$ School of Civil and Transportation Engineering, Henan University of Urban Construction, Pingdingshan 467000, China \\ ${ }^{2}$ School of Civil Engineering, Zhengzhou University, Zhengzhou 450001, China \\ ${ }^{3}$ Henan Joywin Engineering Testing Technology Co., Ltd., Zhengzhou 450000, China \\ ${ }^{4}$ School of Mechanics and Safety Engineering, Zhengzhou University, Zhengzhou 450001, China \\ ${ }^{5}$ School of Civil Engineering, Zhengzhou University of Aeronautics, Zhengzhou 450001, China \\ Correspondence should be addressed to Peibo You; 382618232@qq.com
}

Received 5 May 2020; Revised 11 June 2020; Accepted 17 June 2020; Published 29 July 2020

Academic Editor: Peng Zhang

Copyright (c) 2020 Peibo You et al. This is an open access article distributed under the Creative Commons Attribution License, which permits unrestricted use, distribution, and reproduction in any medium, provided the original work is properly cited.

\begin{abstract}
The steel fiber reinforced concrete (SFRC) shear wall with concrete filled steel tube (CFST) columns is an innovative composite structure. In order to calculate the shear strength of SFRC shear wall with CFST columns, the softened strut and tie model (SSTM) of SFRC shear wall with CFST columns was proposed based on the analysis of shear mechanism of SFRC shear wall with CFST columns. The SSTM was composed of diagonal, horizontal, and vertical mechanisms, in which the contributions of concrete, reinforcement, and steel fiber to the shear strength of SFRC web of shear wall were identified. The shear capacities of 24 shear walls were calculated and compared with the available test results, and reasonable agreement was obtained. The results also showed that the steel fibers distributed randomly in concrete could be treated as longitudinal and transverse reinforcement in the shear strength analysis of SFRC web, and the SSTM was reasonable and useful to analyze and predict the shear strength of SFRC shear wall with CFST columns.
\end{abstract}

\section{Introduction}

Reinforced concrete (RC) shear wall system is a common one to resist lateral force, which has been widely used in the regions of high seismic activity in the past decade. However, due to low tensile strength and large brittleness of normal-strength concrete, the ductility, energy dissipation, and load bearing capacities of RC shear wall are poor. In particular, the transverse dimension of shear wall can be decreased with the application of high strength concrete, but its brittleness increases inevitably. Correspondingly, the higher requirement for the seismic performance of shear wall especially with high strength concrete (HSC) would be put forward. In order to improve the seismic performance of shear wall, the use of RC shear wall with concrete filled steel tube (CFST) columns and steel fiber reinforced concrete (SFRC) shear wall has attracted the interest of structural engineers in recent years.
First, theoretical analysis and experimental study [1-4] show that the CFST columns serving as boundary members can provide the effective constraint to reinforced high strength concrete (RHSC) wall, restrain the cracking development, and also bear part of transverse load after the RHSC wall deteriorates gradually, indicating that the RHSC shear wall with CFST columns can form double-channel seismic line and have favorable seismic performance. Secondly, the application of SFRC is a good way to enhance the seismic behavior of conventional shear wall structure, especially the RHSC shear wall [5]. Several researchers [6-10] have conducted the experiments on the seismic performance of SFRC shear wall. In these experiments, the SFRC shear walls were subjected to reversed cyclic loading. As expected, because SFRC has good properties, such as stretching, shear resistance, cracking resistance, toughness [11], fire resistance, durability $[12,13]$, and earthquake resistance, it can remarkably improve the seismic behavior of RC shear wall 
and reduce the phenomenon of reinforcement congestion and construction difficulty. The load bearing capacity, ductility, and energy dissipation capacities of SFRC shear walls increase with the increasing of steel fiber volume fraction.

In this study, an innovative composite shear wall referred to as SFRC shear wall with CFST columns is introduced, which consists of SFRC web and CFST boundary elements. In this new composite shear wall, SFRC web can mainly improve the ductility and energy dissipation capacities, CFST boundary elements can enhance the load bearing capacity. This kind of composite shear wall will adequately make use of the advantages of SFRC shear wall and CFST columns. In order to more fully understand the seismic behavior of this structure form, six SFRC shear wall with CFST column specimens were tested under constant axial force and reversed cyclic loading. The failure mode of shear wall specimens was analyzed, and the influencing factors, such as the steel fiber volume fraction and concrete strength on the shear strength of shear wall specimens, were studied. Since the load transferring mechanism of shear walls under the combined action of compression, bending, and shearing is very complicated, the researches on the load bearing mechanism and the calculation methods for shear capacity of shear walls are relatively few. In addition, the only existing calculation methods for shear capacity proposed are mostly semiempirical relations based on the experimental results and are lacking in the reasonable theoretical model. Furthermore, the analysis and calculations are not very accurate.

The softened strut and tie model (SSTM) for determining the shear strengths of RC members failing in diagonal compressions was proposed by Hwang and Lee, which originated from the strut and tie concept, considered the compression softening characteristics of concrete, and was derived to satisfy equilibrium, compatibility, and constitutive laws of cracked reinforced concrete [14-19]. The SSTM has been used in shear strength prediction of various kinds of concrete members and the accuracy has been checked by comparing calculated shear strengths with experimental data reported in the previous literature [20-24].

In this paper, the SSTM of SFRC shear wall with CFST columns was proposed based on the analysis for its shear mechanism, in which the steel fibers distributed randomly in concrete were equivalent to the longitudinal and transverse reinforcements. Furthermore, a new calculation method based on the SSTM for the shear strength of SFRC shear wall with CFST columns, RC shear wall with CFST columns, and SFRC shear wall was established. Finally, the shear capacities of 24 low-rise shear walls were calculated and the calculated values showed a reasonable agreement with the available experimental results $[2,4,9,10]$.

\section{General Test Situation}

2.1. Specimen Details. The dimensions and configurations of the shear wall specimens are shown in Figure 1. Each specimen mainly consists of five parts: one SFRC web in the centre, two CFST columns which are located in the right and left sides of middle SFRC web, and two RC beams which are located in the top and bottom sides of middle SFRC web. In order to ensure the reliable connections between the CFST columns and the shear wall web, the U-shaped connectors [25] with the same space as the horizontal reinforcing bars are also welded to the wall of steel tubes. The photos of completed steel frame and U-shaped connector are shown in Figures 2(a) and 2(b), respectively.

The side length and height of the square CFST columns were $120 \mathrm{~mm}$ and $750 \mathrm{~mm}$, respectively. The steel plates for hollow sections of square CFST columns and U-shaped connectors were made by cold-formed steel tubes with the thickness of $3 \mathrm{~mm}$ and $2 \mathrm{~mm}$, respectively. The strength grade of reinforcement was HRB400, and the grade of steel plates was Q235B based on the Chinese code. The material properties of steel bar and plate are listed in Table 1. The steel fiber is hooked at both ends with length of $35 \mathrm{~mm}$, diameter of $0.55 \mathrm{~mm}$, and aspect ratio of 64 .

The test parameters included steel fiber volume fraction $\rho_{\text {sf }}(0,0.5 \%, 1.0 \%$, and $1.5 \%)$ and concrete strength grade (CF40, CF60, and CF80). According to the test parameters, six shear wall specimens were cast, tested, and numbered as SS-1.0-00-C60, SS-1.0-05-CF60, SS-1.0-10-CF60, SS-1.0-15CF60, SS-1.0-10-CF40, and SS-1.0-10-CF80. In the serial number of specimens, the first part SS represents that steel tube and steel fiber; the second part 1.0 refers to the shear span ratio of 1.0, the third part represents the steel fiber volume fraction of the web in shear wall, and the fourth part represents the concrete, in which $\mathrm{C}$ represents plain concrete, whilst CF represents SFRC, and the following number denotes target concrete strength of shear wall specimen. The summary of information of each shear wall specimen is listed in Table 2. The mechanical properties of the harden concrete used in the shear wall of all specimens are also listed in Table 2. All the harden concretes reached its target compressive strength.

2.2. Test Scheme. In the test, the load exerted on the specimens included horizontal and vertical one, and the test setup is shown in Figure 3. The horizontal load was cyclic one and applied by an electrohydraulic servo control actuator on the top beam of specimen; the axial compressive force was kept constant and applied by hydraulic Jack. The target axial compression ratio, $n$, was taken as 0.2 for all specimens. The rolling support between hydraulic Jack and vertical reaction steel frame assured the smooth horizontal slipping of specimens. Rotation control mode was adopted and the typical rotation controlled loading history is shown in Figure 4 . A nominal yield rotation angle $\left(\theta_{\mathrm{ym}}\right)$ was designated to $0.0025 \mathrm{rad}$ according to the research in literature [1], which was corresponding to a nominal yield lateral displacement $\left(\Delta_{\mathrm{ym}}\right)$ at the loading point, $\Delta_{\mathrm{ym}}=\theta_{\mathrm{ym}} \times 750 \mathrm{~mm}=$ $1.875 \mathrm{~mm}$. Before $\theta_{\mathrm{ym}}$, the rotation levels of $0.5 \theta_{\mathrm{ym}}$ and $0.75 \theta_{\mathrm{ym}}$ were imposed. Hereafter, the rotation increment was $0.0025 \mathrm{rad}$ for each rotation level and three cycles were imposed at each rotation level. The tests were conducted under the rotation controlled cyclic loading until the axial compressive force could not be maintained or the lateral force degraded below $85 \%$ of peak lateral load. 

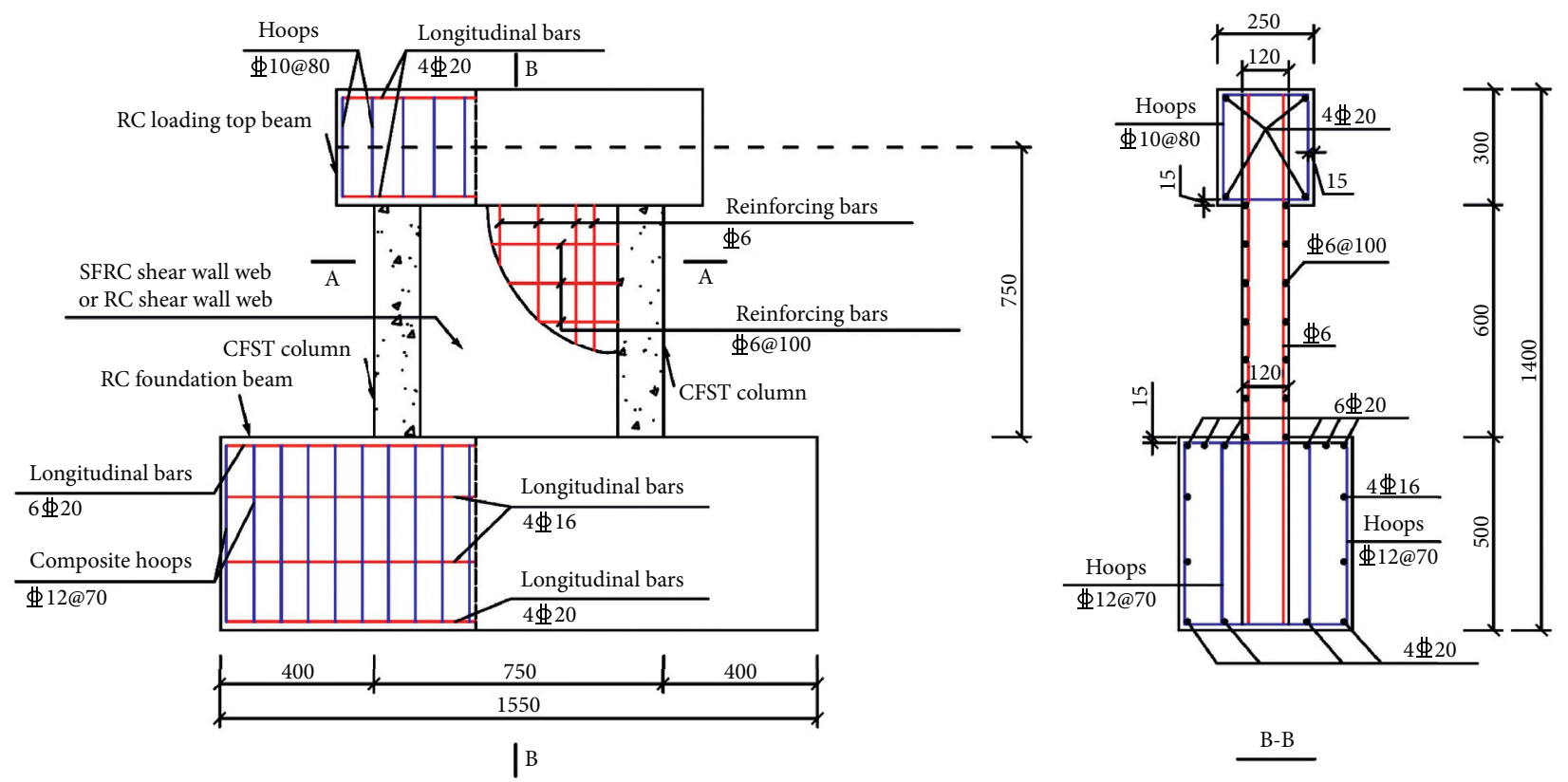

| $\mathrm{B}$

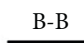

(a)

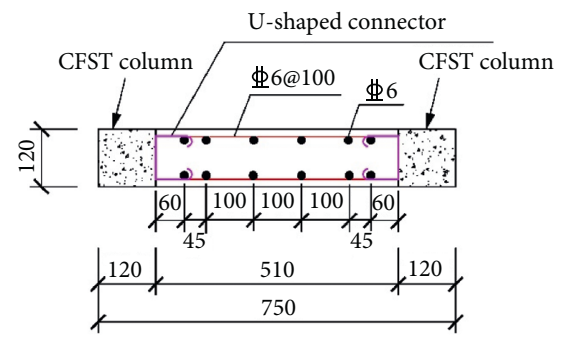

A-A

(b)
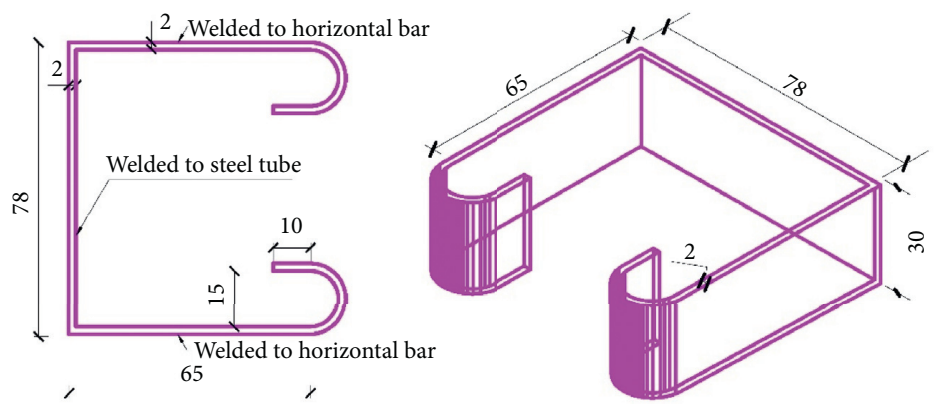

(c)

Figure 1: Specimen configuration (unit: mm). (a) Elevation. (b) A-A section. (c) One-dimensional and three-dimensional graph of Ushaped connector.

2.3. Failure Process. The whole process from the initiation to failure of specimens was observed. During the initial loading period, the inclined cracks gradually appeared and constantly extended under cyclic lateral loading. Then several pairs of visible intercrossing diagonal cracks developed approximately along the diagonal directions of the web in shear wall, the horizontal reinforcing bars in the web of the shear wall yielded successively with the loading, and the diagonal strut mechanism in the web of the shear wall was formed. Hereafter, new cracks seldom occurred and the width of the diagonal cracks at the middle part of the web in shear wall increased rapidly with further loading. The web of the shear wall began to fail in diagonal compression, the concrete in the web was crushed and spalled, and the web lost bearing capacity gradually. Upon further cycles, slight local buckling was observed at the bottom of CFST columns and plastic hinges were formed. Finally, the lateral load rapidly dropped to about $85 \%$ of the peak lateral load and the specimen failed. All specimens mainly exhibited a typical diagonal cracking pattern during the test process and 


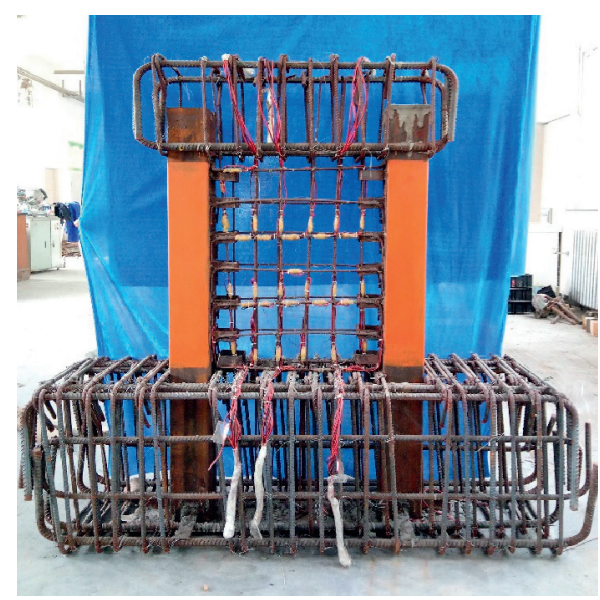

(a)

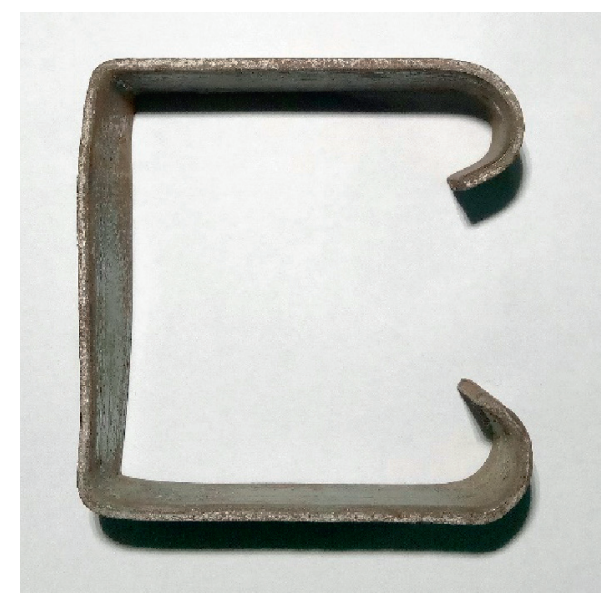

(b)

FIgURE 2: Steel frame and U-shaped connector. (a) Steel frame. (b) U-shaped connector.

TABLE 1: Material properties of steel plate and bar.

\begin{tabular}{lccc}
\hline Type & Yield strength $f_{\mathrm{y}}\left(\mathrm{N} / \mathrm{mm}^{2}\right)$ & Ultimate strength $f_{\mathrm{u}}\left(\mathrm{N} / \mathrm{mm}^{2}\right)$ & Elastic modulus $E_{\mathrm{s}}\left(\mathrm{N} / \mathrm{mm}^{2}\right)$ \\
\hline 3 mm plate & 307.67 & 392.00 & $1.98 \times 10^{5}$ \\
2 mm plate & 236.67 & 323.20 & $1.88 \times 10^{5}$ \\
C 6 bar & 369.17 & 521.60 & $1.85 \times 10^{5}$ \\
\hline
\end{tabular}

TABLE 2: Summary of specimen information.

\begin{tabular}{lcccccc}
\hline Identification number & $\rho_{\text {sf }}(\%)$ & Columns $f_{\mathrm{c}}(\mathrm{MPa})$ & Columns $f_{\mathrm{t}}(\mathrm{MPa})$ & $\mathrm{Web} f_{\mathrm{c}}(\mathrm{MPa})$ & $\mathrm{Web} f_{\mathrm{ft}}(\mathrm{MPa})$ & $V_{\text {jh,test }}(\mathrm{kN})$ \\
\hline SS-1.0-00-C60 & 0 & 55.9 & 2.76 & 56.3 & 2.81 & 902 \\
SS-1.0-05-CF60 & 0.5 & 55.5 & 2.73 & 55.2 & 3.67 & 948 \\
SS-1.0-10-CF60 & 1.0 & 55.5 & 2.74 & 55.1 & 6.15 & 1005 \\
SS-1.0-15-CF60 & 1.5 & 56.0 & 2.77 & 36.5 & 1.88 & 1048 \\
SS-1.0-10-CF40 & 1.0 & 38.1 & 2.15 & 38.3 & 3.78 & 810 \\
SS-1.0-10-CF80 & 1.0 & 64.6 & 3.96 & 65.6 & 6.84 \\
\hline
\end{tabular}

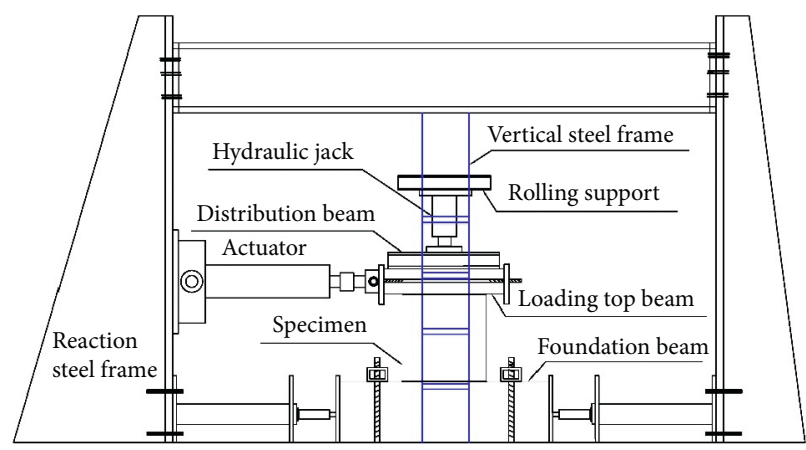

(a)

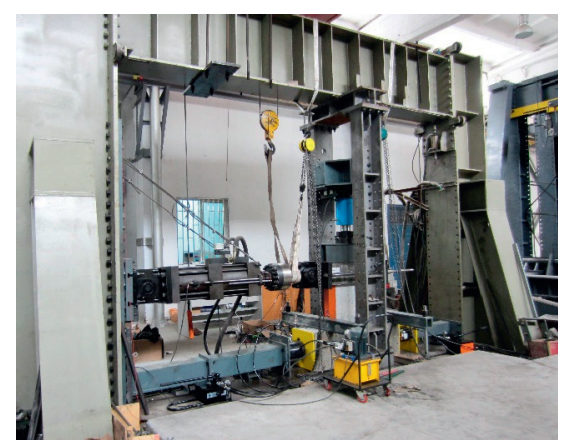

(b)

Figure 3: Test set-up. (a) Schematic view. (b) Test scene.

showed a shear-dominant failure mode. The failure pattern and crack distribution at the peak lateral load and ultimate state (the lateral force degraded to $85 \%$ of the peak lateral load) of all tested specimens are shown in Figure 5.

During the test process, the connections between the CFST columns and web were reliable and no significant separation at the interface occurred, which indicated that the performance of the U-shaped connector designed was effective. Moreover, no evident local buckling on the CFST columns of the SFRC shear wall specimens was observed at the ultimate state. The SFRC shear wall specimens had smaller destruction compared with that without steel fibers, which indicated that the SFRC shear wall specimens had the better repairability. 


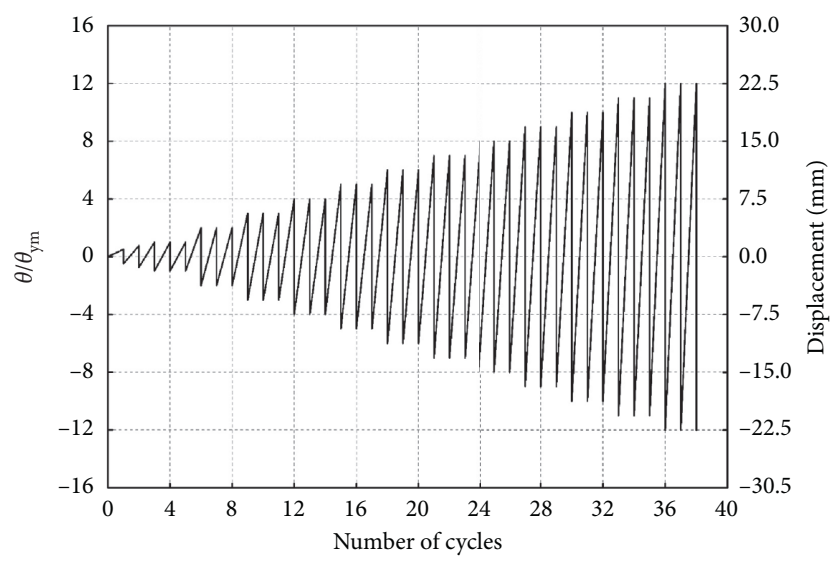

FIgURE 4: Loading history.

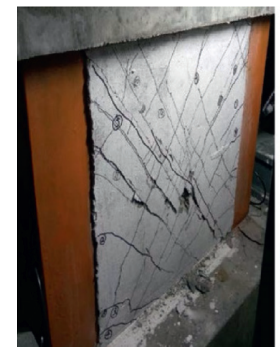

SS-1.0-00-C60

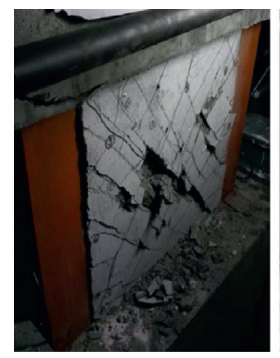

SS-1.0-00-C60

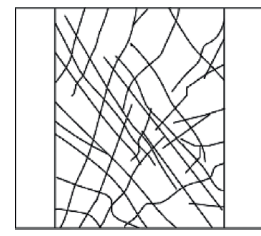

SS-1.0-00-C60

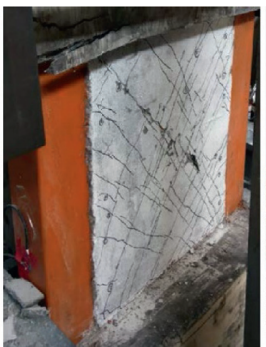

SS-1.0-05-CF60

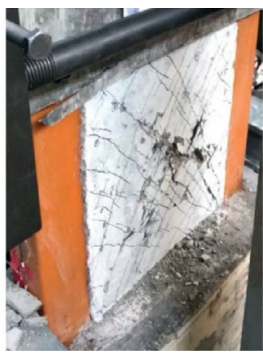

SS-1.0-05-CF60

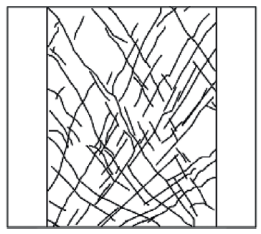

SS-1.0-05-CF60

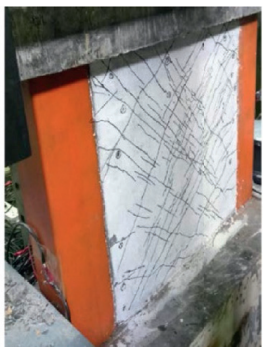

SS-1.0-10-CF60

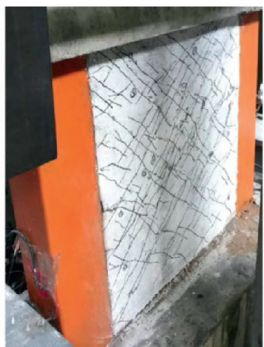

SS-1.0-15-CF60

(a)

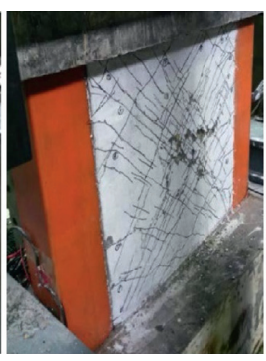

SS-1.0-10-CF60

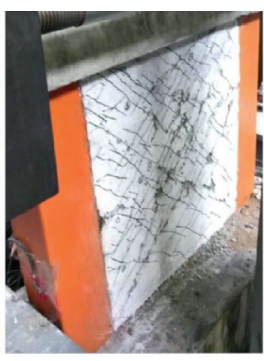

SS-1.0-15-CF60

(b)

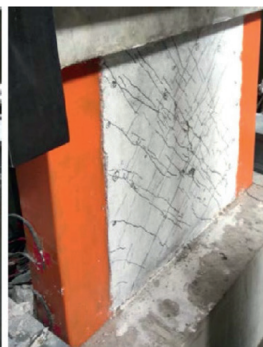

SS-1.0-10-CF40

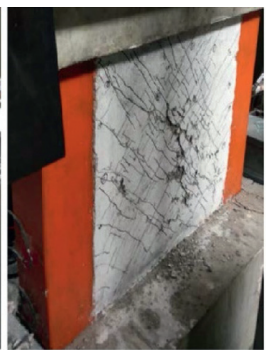

SS-1.0-10-CF40

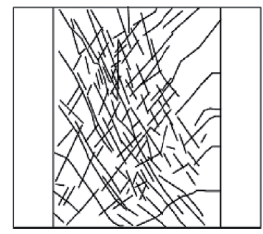

SS-1.0-10-CF40

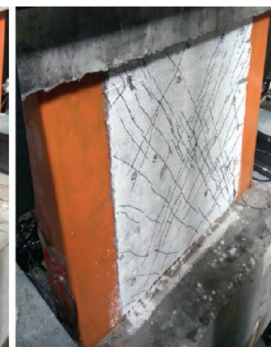

SS-1.0-10-CF80

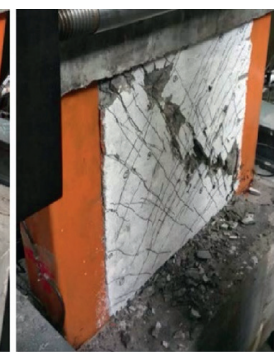

SS-1.0-10-CF80

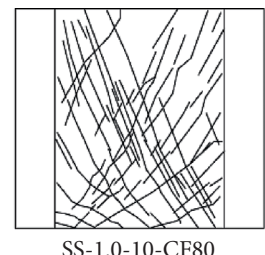

(c)

FIGURE 5: Failure pattern and crack distribution of shear wall specimens. (a) Failure pattern at peak state. (b) Failure pattern at ultimate state. (c) Schematic view of crack distribution.

2.4. Influence Factors. The shear capacities of all specimens are listed in Table 2. It can be seen from Table 2 that the shear performance of specimens is improved obviously with the increase of steel fiber volume fraction from $0 \%$ to $1.5 \%$. Compared with the specimen SS-1.0-00-C60, the shear capacity of specimen SS-1.0-05-CF60, SS-1.0-10-CF60, and SS-1.0-15-CF60 is increased by $5.10 \%, 11.42 \%$, and $16.19 \%$, respectively. In addition, steel fiber could effectively control the crack width and improve the distribution shape of cracks in the web of shear wall. The cracks became much thinner, denser, of more quantity, and wider distribution with the increase of steel fiber volume fraction, whilst the crushing and spalling of concrete were also reduced. For instance, the maximum crack width of RC shear wall specimen numbered 
SS-1.0-00-C60 was $2.0 \mathrm{~mm}$ at the peak load, whilst the maximum crack width of SFRC shear wall specimen numbered SS-1.0-05-CF60, SS-1.0-10-CF60, and SS-1.0-15CF60 was $1.6 \mathrm{~mm}, 1.2 \mathrm{~mm}$, and $1.0 \mathrm{~mm}$, respectively. The maximum crack width decreased significantly with the increase of steel fiber volume fraction; the similar results were reported in the literature $[9,10]$.

Furthermore, it can be seen from Table 2 that the shear performance of specimens is improved obviously with the enhancing of concrete strength from CF40 to CF80. Compared with the specimen SS-1.0-10-CF40, the shear capacity of SS-1.0-10-CF60 and SS-1.0-10-CF80 is increased by $24.07 \%$ and $36.67 \%$, respectively. And as shown in Figure 5, the SFRC shear wall specimens with different concrete strength had the similar failure appearance at the peak and ultimate state under the condition of the same steel fiber volume fraction. It can be seen that the lateral load of SFRC shear wall specimen with higher strength concrete deteriorated more obviously after the peak load, the crushing, and spalling of concrete were more serious at the ultimate state, especially for the specimen SS-1.0-00-CF80.

\section{Shear Resisting Mechanism of SFRC Shear Wall with CFST Columns}

It was observed in the test that the failing process of SFRC shear wall with CFST columns can be divided into two stages: at early loading stage, the all bending moments acted on the SFRC shear wall with CFST columns were carried by the CFST columns, nearly all the horizontal shear forces were carried by the web, and the axial forces were shared by the CFST columns and web; at medium and late loading stage, the concrete in the web continuously cracked, resulting in a decrease of the stiffness, and the shear forces gradually transferred from the web to CFST columns. Therefore, the calculation method for shear strength of SFRC shear wall with CFST columns can be defined as

$$
V_{\text {jh,calc }}=V_{\text {jh }}+V_{\text {col }} \text {, }
$$

where $V_{\text {jh,calc }}$ is the calculated value for shear strength of SFRC shear wall with CFST columns; $V_{\text {jh }}$ is the shear strength of web; and $V_{\text {col }}$ is the shear strength of CFST columns.

The shear strength of CFST columns can be defined as [4]

$$
V_{\mathrm{col}}=\alpha_{\mathrm{v}} \cdot A_{\mathrm{sc}} \cdot \tau_{\mathrm{scy}},
$$

where $\alpha_{\mathrm{v}}$ is the calculation coefficient for shear capacity, $\alpha_{\mathrm{v}}=0.97+0.2 \operatorname{In}(\xi), \xi$ is the confinement factor, $\xi=\alpha_{\mathrm{s}} f_{\mathrm{y}} / f_{\mathrm{c}}, f_{\mathrm{y}}$ is the yield strength of steel tube, $f_{\mathrm{c}}$ is the axial compressive strength of concrete, $\alpha_{\mathrm{s}}$ is the steel ratio of CFST column, $\alpha_{\mathrm{s}}=A_{\mathrm{s}}^{\prime} / A_{\mathrm{c}}^{\prime}, A_{\mathrm{s}}^{\prime}$ and $A_{\mathrm{c}}^{\prime}$ are the cross-sectional areas of steel tube and concrete, respectively, $A_{\mathrm{sc}}$ is the total cross-sectional area of CFST column, and $\tau_{\mathrm{scy}}$ is the shear yield limit, $\tau_{\text {scy }}=\left(0.422+0.313 \alpha_{\mathrm{s}}^{2.33}\right) \xi^{0.134}(1.14+1.02 \xi) f_{\mathrm{c}}$.

The load transferring mechanism of SFRC web under the combined action of compression, bending, and shearing is very complicated, which is similar to $\mathrm{RC}$ web in the literature $[2,3]$. In the SSTM, the shear strength of the web is assumed to be that of concrete compressive struts, and the concrete in the web can continue to withstand shear force after the tension ties yield. Therefore, the main characteristic of web failure is that the concrete in the web reaches its compressive strength and is crushed and spalled. For diagonal compression failure, the shear strength of the web is defined as the concrete compressive stress on the nodal zone as the concrete reaches its capacity. The concrete bearing capacity is the summation of compressions from the concrete compressive struts in the diagonal, horizontal, and vertical mechanisms [14-19]. Hence, three strut and tie load paths are proposed to simulate the force transfer within the web, including the diagonal, horizontal, and vertical mechanisms, as shown in Figure 6.

The concrete in the web is subjected to the compression force; thus the diagonal compressive strut is formed, as shown in Figure 6(a). Due to the higher tensile strength of SFRC, the diagonal tension forces in the web are mainly carried by the SFRC before the cracking of concrete, the action of reinforcing bars is much smaller at this time. The initial inclined cracks in the web occur when the diagonal tension force is greater than the tensile strength of concrete. After the initial cracking of concrete, the diagonal tension forces in the web are mainly carried by the horizontal and vertical ties. The horizontal ties are composed of horizontal reinforcing bars and steel fibers as shown in Figure 6(b), whilst the vertical ties are composed of vertical reinforcing bars and steel fibers as shown in Figure 6(c). In summary, the reinforcing bars and steel fibers are subjected to tension and the concrete acts as compressive struts after the development of the first cracking pattern in the web; thus a strut and tie action is formed.

The diagonal mechanism (Figure 6(a)) is a single SFRC diagonal compression strut whose angle of inclination $\theta$ is defined as

$$
\theta=\tan ^{-1}\left(\frac{H}{l}\right)
$$

where $H$ is the distance from the lateral force loading point to the shear wall base; $l$ is internal lever arm of the vertical shear couple, $l=0.8 l_{\mathrm{w}}$; and $l_{\mathrm{w}}$ is the length of the entire web in the direction of the applied lateral force.

The effective area of the SFRC diagonal compression strut $A_{\text {str }}$ is defined as

$$
A_{\text {str }}=\alpha_{\mathrm{s}} \times b_{\mathrm{s}},
$$

where $a_{\mathrm{s}}$ is the depth of diagonal strut and $b_{\mathrm{s}}$ is the width of diagonal strut that can be taken as the width of the web $t_{\mathrm{w}}$.

The depth of the diagonal strut $a_{\mathrm{s}}$ depends on its end condition provided by the compression zone at the base of the web. It can be intuitively assumed that

$$
\alpha_{\mathrm{s}}=\alpha_{\mathrm{w}}
$$

where $a_{\mathrm{w}}$ is the depth of the compression zone at the base of the web, which can be approximately determined by [15]

$$
\alpha_{\mathrm{w}}=\left(0.25+0.85 \frac{N^{\prime}}{A_{\mathrm{w}} f_{\mathrm{c}}^{\prime}}\right) l_{\mathrm{w}},
$$




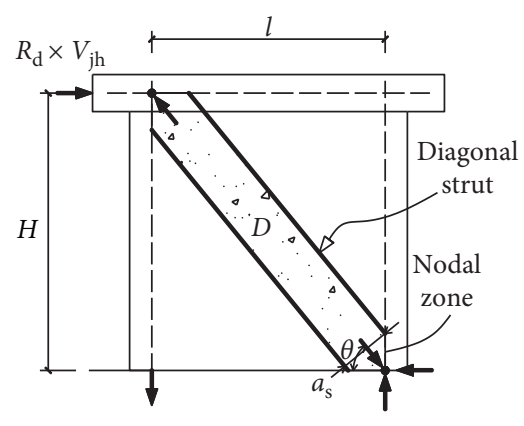

(a)

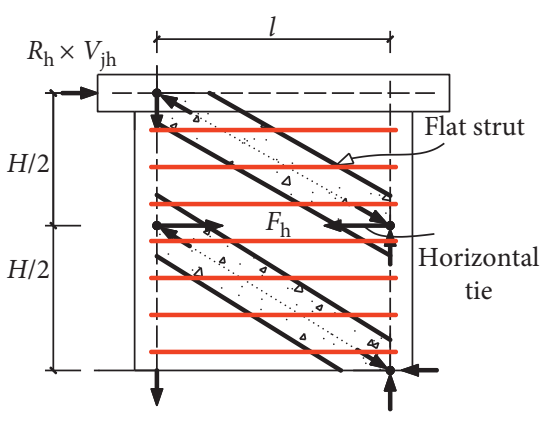

(b)

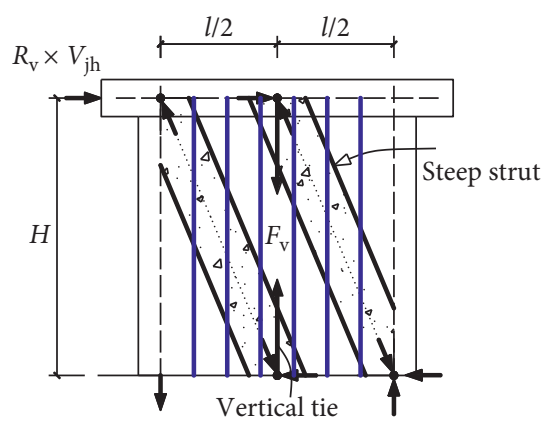

(c)

FIgURE 6: Shear resisting mechanisms of web. (a) Diagonal. (b) Horizontal. (c) Vertical.

where $N^{\prime}$ is the axial compressive force for the web; $A_{\mathrm{w}}$ is the cross-sectional area of the web, $A_{\mathrm{w}}=t_{\mathrm{w}} \times l_{\mathrm{w}}$; and $f_{\mathrm{c}}^{\prime}$ is the compressive strength of a standard concrete cylinder (MPa).

The axial compressive force for the web $N^{\prime}$ can be calculated as

$$
N^{\prime}=\frac{0.85 E_{\mathrm{c}} t_{\mathrm{w}} l_{\mathrm{w}}}{0.85 E_{\mathrm{c}} t_{\mathrm{w}} l_{\mathrm{w}}+2 E_{\mathrm{s}}^{\prime} A_{\mathrm{s}}^{\prime}+2 E_{\mathrm{c}}^{\prime} A_{\mathrm{c}}^{\prime}} N,
$$

where $N$ is the axial compressive force for the shear wall specimen; $E_{\mathrm{c}}$ is the elastic modulus of web concrete; 0.85 is the reduction coefficient of axial compressive stiffness for web concrete [4]; $E_{\mathrm{s}}^{\prime}$ is the elastic modulus of steel tube; and $E_{c}^{\prime}$ is the elastic modulus of concrete inside the steel tube.

The horizontal mechanism (Figure 6(b)) includes one horizontal tie and two flat struts. Since steel fiber improves the tensile strength of the concrete, which makes the performance of SFRC shear wall different from that of RC shear wall. The horizontal tie is made up of the horizontal reinforcing bars and steel fibers and can be described as the following:

$$
F_{\mathrm{h}}=F_{\mathrm{s}, \mathrm{h}}+F_{\mathrm{sf}, \mathrm{h}},
$$

where $F_{\mathrm{h}}$ is the tension force in the horizontal tie; $F_{\mathrm{s}, \mathrm{h}}$ is the tension force of horizontal reinforcing bars, $F_{\mathrm{s}, \mathrm{h}}=A_{\mathrm{s}, \mathrm{h}} \times f_{\mathrm{s}, \mathrm{h}}$; $A_{\mathrm{s}, \mathrm{h}}$ is the sectional area of horizontal reinforcing bars; $f_{\mathrm{s}, \mathrm{h}}$ is the tensile strength of horizontal reinforcement; $F_{\text {sf,h }}$ is the tension force of horizontal steel fibers, $F_{\mathrm{sf}, \mathrm{h}}=A_{\mathrm{sf}, \mathrm{h}} \times f_{\mathrm{sf}} ; A_{\mathrm{sf}, \mathrm{h}}$ is the sectional area of horizontal steel fibers; and $f_{\text {sf }}$ is the tensile strength of steel fiber.

The experimental results indicated that the horizontal reinforcing bars in the web did not fully yield when the web damaged, so the effective coefficient for shear resistance of horizontal reinforcement, $\eta_{1}$, is introduced. Thus $F_{\mathrm{s}, \mathrm{h}}$ can be defined as $F_{\mathrm{s}, \mathrm{h}}=\eta_{1} \times A_{\mathrm{s}, \mathrm{h}} \times f_{\mathrm{s}, \mathrm{h}}$, where $\eta_{1}$ is taken as 0.75 based on the analysis for the test results in the literature [15].

For simplicity, the steel fibers randomly distributed in the three dimensions of the web can be equivalent to horizontal and vertical microreinforcing bars, as shown in Figure 7. Thus, the sectional area of horizontal steel fibers, $A_{\text {sf,h }}$, can be defined as

$$
A_{\mathrm{sf}, \mathrm{h}}=n_{\mathrm{sf}} A_{\mathrm{sf}},
$$

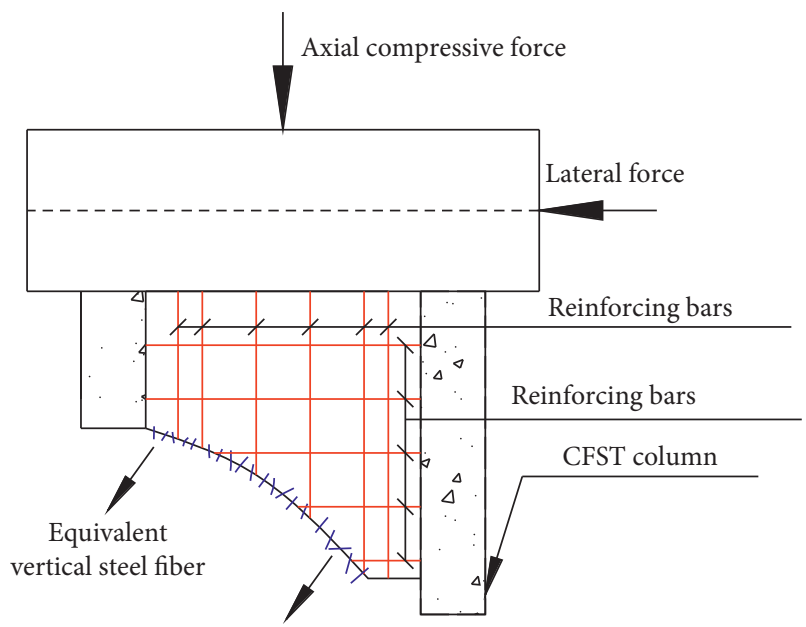

Equivalent horizontal steel fiber

Figure 7: Steel fiber ties.

where $A_{\mathrm{sf}}$ is the cross-sectional area of a single steel fiber and $n_{\mathrm{sf}}$ is the equivalent steel fiber number, which can be calculated as

$$
n_{\mathrm{sf}}=\eta_{2} \rho_{\mathrm{sf}} \frac{t_{\mathrm{w}} \quad H}{A_{\mathrm{sf}} \sin \theta},
$$

where $\rho_{\text {sf }}$ is the steel fiber volume fraction and $\eta_{2}$ is the equivalent coefficient, which can be approximately designated as 0.41 according to the study in the literature [26].

The sectional area of horizontal steel fibers, $A_{\mathrm{sf}, \mathrm{h}}$, can be determined as

$$
A_{\mathrm{sf}, \mathrm{h}}=\frac{0.41 \rho_{\mathrm{sf}} t_{\mathrm{w}} H}{\sin \theta} .
$$

The vertical mechanism (Figure 6(c)) is composed of one vertical tie and two steep struts. Similar to the horizontal tie, the vertical tie includes the vertical reinforcing bars and steel fibers within the web and can be described as the following:

$$
F_{\mathrm{v}}=F_{\mathrm{s}, \mathrm{v}}+F_{\mathrm{sf}, \mathrm{v}},
$$

where $F_{\mathrm{v}}$ is the tension force in the vertical tie; $F_{\mathrm{s}, \mathrm{v}}$ is the tension force of vertical reinforcing bars, $F_{\mathrm{s}, \mathrm{v}}=A_{\mathrm{s}, \mathrm{v}} \times f_{\mathrm{s}, \mathrm{v}} ; A_{\mathrm{s}, \mathrm{v}}$ is the sectional area of vertical reinforcing bars; $f_{\mathrm{s}, \mathrm{v}}$ is the tensile strength of vertical reinforcement; $F_{\mathrm{sf}, \mathrm{v}}$ is the tension force of 
vertical steel fibers, $F_{\mathrm{sffv}}=A_{\mathrm{sffv}} \times f_{\mathrm{sf}} ; A_{\mathrm{sfv}}$ is the sectional area of vertical steel fibers; and $A_{\mathrm{sf}, \mathrm{v}}=0.41 \rho_{\mathrm{sf}} t_{\mathrm{w}} l_{\mathrm{w}} / \cos \theta$ based on the above analysis.

The research in literature [15] shows that the vertical reinforcing bars are not fully effective in constituting the vertical tie, and the effective coefficient for shear resistance of vertical reinforcing bars, $\eta_{3}$, is introduced. Thus, $F_{\mathrm{s}, \mathrm{v}}$ can be defined as $F_{\mathrm{s}, \mathrm{v}}=\eta_{3} \times A_{\mathrm{s}, \mathrm{v}} \times f_{\mathrm{s}, \mathrm{v}}$, where $\eta_{3}$ is taken as 0.8 [15].

\section{Calculation Method for Shear Strength of SFRC Shear Wall with CFST Columns}

The SSTM is used to determine the shear strength of web failing in diagonal compression.

4.1. Equilibrium Conditions. Based on the proposed strut and tie model for a web of shear wall, the horizontal and vertical shear forces can be calculated as follows:

$$
\begin{aligned}
& V_{\text {jh }}=D \cos \theta+F_{\mathrm{h}}+F_{\mathrm{v}} \cot \theta, \\
& V_{\mathrm{jv}}=D \sin \theta+F_{\mathrm{v}}+F_{\mathrm{h}} \tan \theta,
\end{aligned}
$$

where $V_{\mathrm{jh}}$ is the horizontal shear force; $V_{\mathrm{jv}}$ is the vertical shear force; and $D$ is the compression force in SFRC diagonal strut. The details of force diagram are shown in Figure 8.

The ratios of the horizontal shear $V_{\mathrm{jh}}$ assigned among the three resisting mechanisms can be defined as [15]

$$
D \cos \theta: F_{\mathrm{h}}: F_{\mathrm{v}} \cot \theta=R_{\mathrm{d}}: R_{\mathrm{h}}: R_{\mathrm{v}} \text {, }
$$

where $R_{\mathrm{d}}, R_{\mathrm{h}}$, and $R_{\mathrm{v}}$ are the web shear ratios resisted by the diagonal, horizontal, and vertical mechanisms, respectively, which can be defined as the following [15]:

$$
\begin{aligned}
& R_{d}=\frac{\left(1-\gamma_{\mathrm{h}}\right)\left(1-\gamma_{\mathrm{v}}\right)}{1-\gamma_{\mathrm{h}} \gamma_{\mathrm{v}}}, \\
& R_{h}=\frac{\gamma_{\mathrm{h}}\left(1-\gamma_{\mathrm{v}}\right)}{1-\gamma_{\mathrm{h}} \gamma_{\mathrm{v}}} \\
& R_{\mathrm{v}}=\frac{\gamma_{\mathrm{v}}\left(1-\gamma_{\mathrm{h}}\right)}{1-\gamma_{\mathrm{h}} \gamma_{\mathrm{v}}}
\end{aligned}
$$

where $\gamma_{\mathrm{h}}$ is the fraction of horizontal shear transferred by the horizontal tie in the absence of the vertical tie and $\gamma_{\mathrm{v}}$ is the fraction of vertical shear carried by the vertical tie in the absence of the horizontal tie. The values of $\gamma_{\mathrm{h}}$ and $\gamma_{\mathrm{v}}$ can be obtained as [27]

$$
\begin{array}{ll}
\gamma_{\mathrm{h}}=\frac{2 \tan \theta-1}{3}, & \text { for } 0 \leq \gamma_{\mathrm{h}} \leq 1, \\
\gamma_{\mathrm{h}}=\frac{2 \tan \theta-1}{3}, & \text { for } 0 \leq \gamma_{\mathrm{h}} \leq 1 .
\end{array}
$$

By solving (13)-(15), the values of $D, F_{\mathrm{h}}$, and $F_{\mathrm{v}}$ can be obtained as

$$
\begin{aligned}
& D=\frac{1}{\cos \theta} \times\left(\frac{R_{\mathrm{d}}}{R_{\mathrm{d}}+R_{\mathrm{h}}+R_{\mathrm{v}}}\right) \times V_{\mathrm{jh}}, \\
& F_{\mathrm{h}}=\left(\frac{R_{\mathrm{h}}}{R_{\mathrm{d}}+R_{\mathrm{h}}+R_{\mathrm{v}}}\right) \times V_{\mathrm{jh}}, \\
& F_{\mathrm{v}}=\frac{1}{\cot \theta} \times\left(\frac{R_{\mathrm{v}}}{R_{\mathrm{d}}+R_{\mathrm{h}}+R_{\mathrm{v}}}\right) \times V_{\mathrm{jh}} .
\end{aligned}
$$

To check whether the web of shear wall reached failure strength, the bearing pressure on the nodal zone (Figure 6), where the compressive forces from the diagonal, flat, and steep struts intersect (Figure 8), must be checked. The maximum compressive stress $\sigma_{\mathrm{d} \text {,max }}$ acting on the nodal zone can be calculated as

$$
\begin{aligned}
\sigma_{d, \max }= & \frac{1}{A_{\text {str }}}\left[D+\frac{F_{\mathrm{h}}}{\cos \theta}\left(1-\frac{\sin ^{2} \theta}{2}\right)\right. \\
& \left.+\frac{F_{v}}{\sin \theta}\left(1-\frac{\cos ^{2} \theta}{2}\right)\right] .
\end{aligned}
$$

4.2. Constitutive Laws. The softened stress-strain relation of cracked SFRC concrete can be represented as the following [28]:

$$
\sigma_{d}=\zeta f_{\mathrm{c}}^{\prime}\left[2\left(\frac{\varepsilon_{\mathrm{d}}}{\zeta \varepsilon_{0}}\right)-\left(\frac{\varepsilon_{\mathrm{d}}}{\zeta \varepsilon_{0}}\right)^{2}\right], \quad \text { for } \frac{\varepsilon_{\mathrm{d}}}{\zeta \varepsilon_{0}} \leq 1,
$$

where $\sigma_{\mathrm{d}}$ is the average principal stress of concrete in the $\mathrm{d}$-direction; $\zeta$ is the softening coefficient; $\varepsilon_{\mathrm{d}}$ is the average principal strain in the d-direction; and $\varepsilon_{0}$ is the concrete cylinder strain corresponding to the cylinder strength $f_{\mathfrak{c}}^{\prime}$, which can be defined approximately as [29]

$$
\varepsilon_{0}=-0.002-0.001\left(\frac{f_{\mathrm{c}}^{\prime}-20}{80}\right), \quad \text { for } 20 \mathrm{MPa} \leq f_{\mathrm{c}}^{\prime} \leq 100 \mathrm{MPa} \text {. }
$$

The softening coefficient $\zeta$ can be calculated as [28]

$$
\zeta=\frac{5.8}{\sqrt{f_{\mathrm{c}}^{\prime}}} \frac{1}{\sqrt{1+400 \varepsilon_{\mathrm{r}}}} \leq \frac{0.9}{\sqrt{1+400 \varepsilon_{\mathrm{r}}}},
$$

where $\varepsilon_{\mathrm{r}}$ is the average principal strain in the r-direction.

Whether the shear strength of the web of shear wall reaches the compressive stress, the strain of the concrete diagonal strut can be conformed by the following formula:

$$
\begin{gathered}
\sigma_{d}=\zeta f_{\mathrm{c}}^{\prime}, \\
\varepsilon_{\mathrm{d}}=\zeta \varepsilon_{0} .
\end{gathered}
$$

The stress-strain relation of reinforcing bar can be described as

$$
\begin{cases}f_{\mathrm{s}}=E_{\mathrm{s}} \varepsilon_{\mathrm{s}}, & \varepsilon_{\mathrm{s}}<\varepsilon_{\mathrm{y}}, \\ f_{\mathrm{s}}=f_{\mathrm{y}}, & \varepsilon_{\mathrm{s}} \geq \varepsilon_{\mathrm{y}},\end{cases}
$$




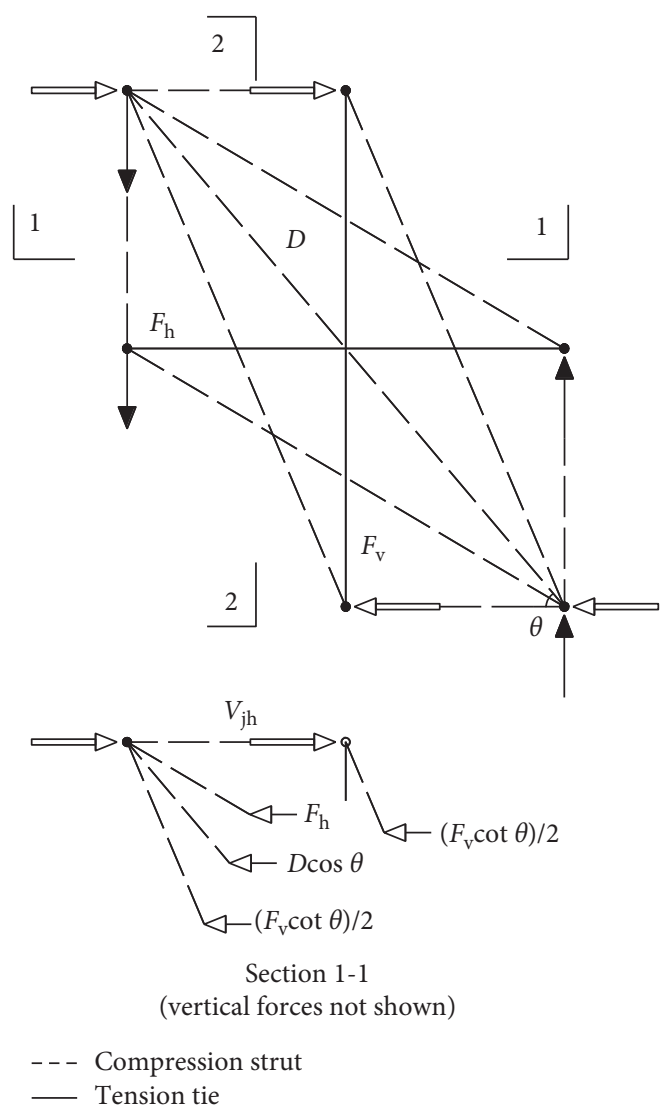

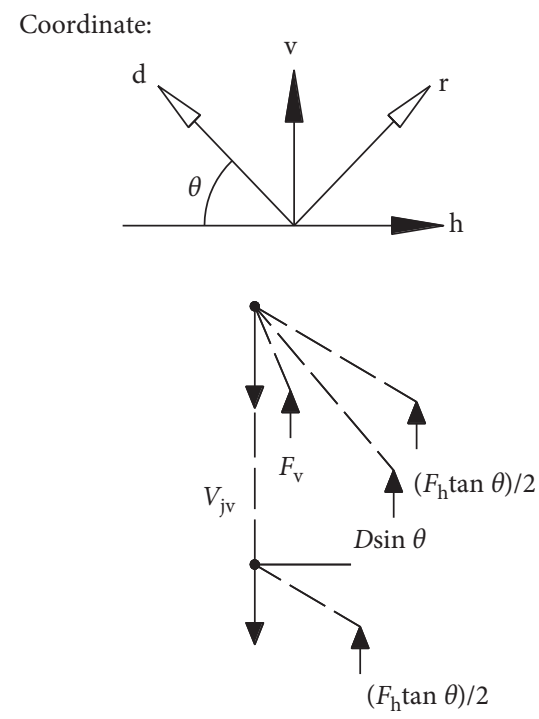

Section 2-2

(horizontal forces not shown)

FIGURE 8: Strut and tie model for the web of shear wall.

where $E_{\mathrm{s}}$ is the elastic modulus of reinforcing bars; $f_{\mathrm{y}}$ is the yield strength of reinforcing bars; and $f_{\mathrm{s}}$ and $\varepsilon_{\mathrm{s}}$ are the stress and strain in mild steel, respectively. $f_{\mathrm{s}}$ becomes $f_{\mathrm{s}, \mathrm{h}}$ or $f_{\mathrm{s}, \mathrm{v}}, E_{\mathrm{s}}$ becomes $E_{\mathrm{s}, \mathrm{h}}$ or $E_{\mathrm{s}, \mathrm{v}}, \varepsilon_{\mathrm{s}}$ becomes $\varepsilon_{\mathrm{s}, \mathrm{h}}$ or $\varepsilon_{\mathrm{s}, \mathrm{v}}$, and $f_{\mathrm{y}}$ becomes $f_{\mathrm{yh}}$ or $f_{\mathrm{yv}}$ when equation (30) is applied to horizontal or vertical reinforcing bars, respectively.

The stress-strain relation of steel fiber can be expressed as

$$
f_{\mathrm{sf}}=E_{\mathrm{sf}} \varepsilon_{\mathrm{sf}},
$$

where $E_{\mathrm{sf}}$ is the elastic modulus of steel fiber and $f_{\mathrm{sf}}$ and $\varepsilon_{\mathrm{sf}}$ are the stress and strain of steel fiber, respectively.

The experiment results show that steel fibers are usually pulled out from concrete rather than broken due to their good tensile strength. Thus, the shear resistant action of the steel fiber depends on the bond strength between steel fiber and concrete. The stress of steel fiber, $f_{\mathrm{sf}}$, should satisfy the relationship as the following:

$$
A_{\text {sf }} f_{\text {sf }} \leq \lambda_{\text {sf }} A_{\text {spf }} \tau_{\text {sf, max }},
$$

where $\tau_{\text {sf,max }}$ is the maximum bond strength between steel fiber and concrete, $\tau_{\mathrm{sf} \text { max }}=2.5 f_{\mathrm{ct}}[30] ; f_{\mathrm{ct}}$ is the matrix tensile strength of SFRC; $\lambda_{\text {sf }}$ is the influence coefficient of steel fiber type; the values of $\lambda_{\text {sf }}$ for long straight, wave-shaped, and hooked steel fibers are $0.5,0.75$, and 1.0 , respectively; $A_{\text {spf }}$ is the surface area of steel fiber, $A_{\mathrm{spf}}=\pi d_{\mathrm{sf}} l_{\text {sfo }} ; d_{\mathrm{sf}}$ is the nominal diameter of steel fiber; $l_{\text {sfo }}$ is the effective anchorage length of steel fiber, $l_{\mathrm{sfo}}=0.25 l_{\mathrm{s}}$; and $l_{\mathrm{sf}}$ is the length of steel fiber.

By adopting equation (33), the stress of steel fiber $f_{\mathrm{sf}}$ can be defined as

$$
f_{\mathrm{sf}} \leq \lambda_{\mathrm{sf}}\left(\frac{l_{\mathrm{sf}}}{d_{\mathrm{sf}}}\right) \tau_{\mathrm{sf}, \max }
$$

The relationship between forces and strains of the tension ties becomes

$$
\begin{gathered}
F_{\mathrm{h}}=F_{\mathrm{s}, \mathrm{h}}+F_{\mathrm{sf}, \mathrm{h}}=0.75 A_{\mathrm{s}, \mathrm{h}} E_{\mathrm{s}, \mathrm{h}} \varepsilon_{\mathrm{s}, \mathrm{h}}+\frac{0.41 \rho_{\mathrm{sf}} t_{\mathrm{w}} H E_{\mathrm{sf}} \varepsilon_{\mathrm{sf}, \mathrm{h}}}{\sin \theta} \leq F_{\mathrm{yh}}, \\
F_{\mathrm{v}}=F_{\mathrm{s}, \mathrm{v}}+F_{\mathrm{sf}, \mathrm{v}}=0.8 A_{\mathrm{s}, \mathrm{v}} E_{\mathrm{s}, \mathrm{v}} \varepsilon_{\mathrm{s}, \mathrm{v}}+\frac{0.41 \rho_{\mathrm{sf}} t_{\mathrm{w}} l_{\mathrm{w}} E_{\mathrm{sf}} \varepsilon_{\mathrm{sf}, \mathrm{v}}}{\cos \theta} \leq F_{\mathrm{yv}}, \\
\varepsilon_{\mathrm{s}, \mathrm{h}}=\varepsilon_{\mathrm{sf}, \mathrm{h}}=\varepsilon_{\mathrm{h}}, \\
\varepsilon_{\mathrm{s}, \mathrm{v}}=\varepsilon_{\mathrm{sf}, \mathrm{v}}=\varepsilon_{\mathrm{v}},
\end{gathered}
$$

where $\varepsilon_{\mathrm{s}, \mathrm{h}}$ and $\varepsilon_{\mathrm{sf}, \mathrm{h}}$ are the strains of the reinforcing bars and the steel fibers in the h-direction, respectively; $\varepsilon_{\mathrm{s}, \mathrm{v}}$ and $\varepsilon_{\mathrm{sff}, \mathrm{v}}$ are the strains of the reinforcing bars and the steel fibers in the $\mathrm{v}$-direction, respectively; $\varepsilon_{\mathrm{h}}$ and $\varepsilon_{\mathrm{v}}$ are the average normal strains in the h- and v-directions, respectively; and $F_{\mathrm{yh}}$ and 


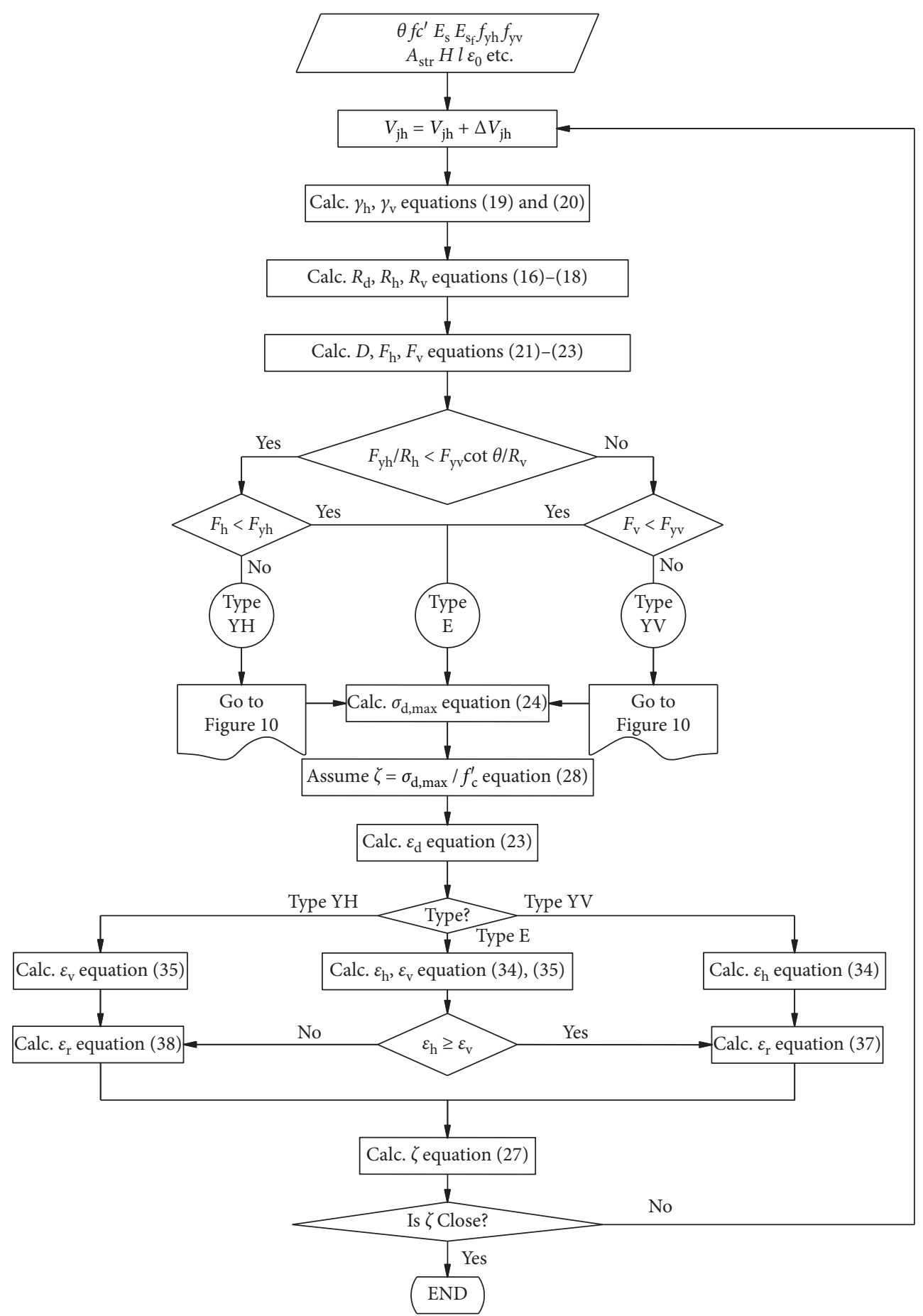

Figure 9: Flow chart showing efficient algorithm.

$F_{\mathrm{yv}}$ are the yielding forces of the horizontal and vertical ties, respectively.

4.3. Compatibility Condition. The compatibility conditions adopted herein are given as the following [31]:

$$
\begin{aligned}
& \varepsilon_{\mathrm{r}}=\varepsilon_{\mathrm{h}}+\left(\varepsilon_{\mathrm{h}}-\varepsilon_{\mathrm{d}}\right) \cot ^{2} \theta, \\
& \varepsilon_{\mathrm{r}}=\varepsilon_{\mathrm{v}}+\left(\varepsilon_{\mathrm{v}}-\varepsilon_{\mathrm{d}}\right) \tan ^{2} \theta .
\end{aligned}
$$

4.4. Solution Procedures. The solution procedures are proposed $[15,19]$, as shown in Figures 9 and 10. The algorithm in Figure 9 starts with a selection of the horizontal shear $V_{\text {jh }}$ and consists of three major steps. Firstly, $\sigma_{\mathrm{d} \text {,max }}$ is calculated by employing the equilibrium equations. By assuming the strength of the concrete strut is reached, an initial value of the softening coefficient $\zeta$ is obtained through $\zeta=\sigma_{\mathrm{d} \text {, max }} / f_{\mathrm{c}}^{\prime}$. Secondly, the strains of the struts and ties are calculated by applying the corresponding constitutive laws. Finally, the 


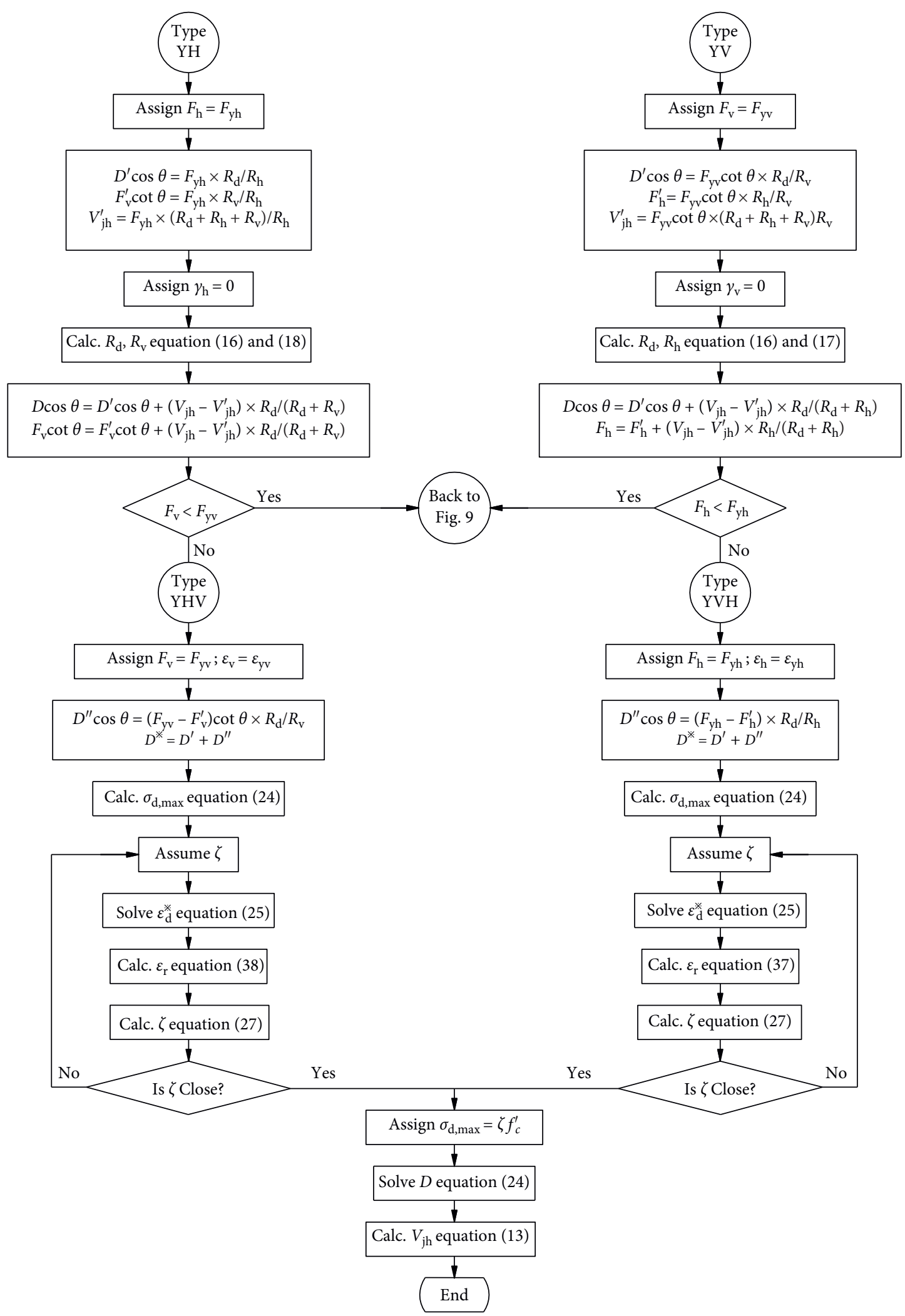

FIgURE 10: Algorithm for postyielding cases.

TABLe 3: Calculation type.

\begin{tabular}{lccccc}
\hline Type & Type E & Type YH & Type YV & Type YHV & Type YVH \\
\hline Condition & $F_{\mathrm{h}}<F_{\mathrm{yh}}$ and $F_{\mathrm{v}}<F_{\mathrm{yv}}$ & $F_{\mathrm{h}}=F_{\mathrm{yh}}$ and $F_{\mathrm{v}}<F_{\mathrm{yv}}$ & $F_{\mathrm{h}}<F_{\mathrm{yh}}$ and $F_{\mathrm{v}}=F_{\mathrm{yv}}$ & $F_{\mathrm{h}}=F_{\mathrm{yh}}$ and then $F_{\mathrm{v}}=F_{\mathrm{yv}}$ & $F_{\mathrm{v}}=F_{\mathrm{yv}}$ and then $F_{\mathrm{h}}=F_{\mathrm{yh}}$ \\
\hline
\end{tabular}




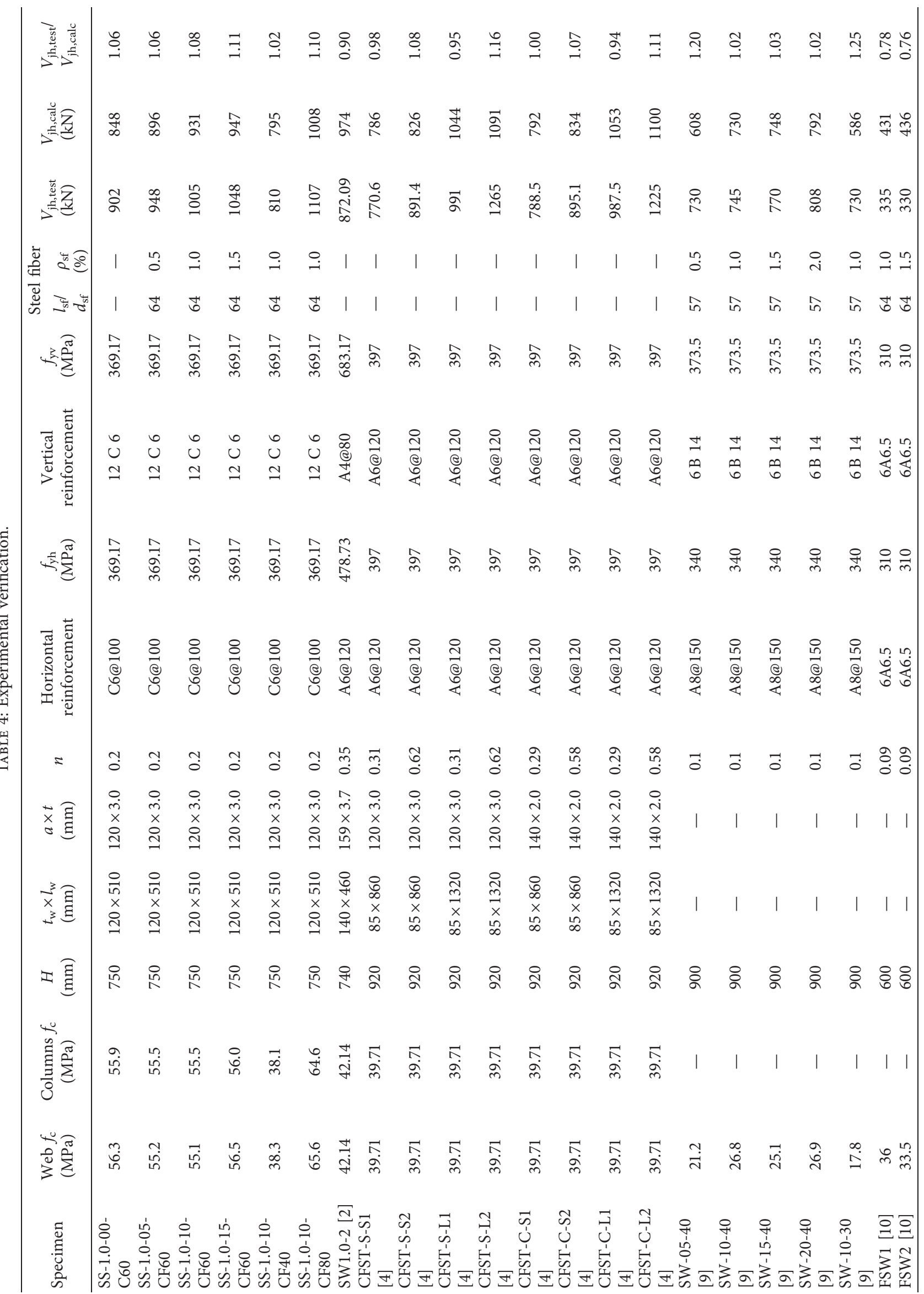




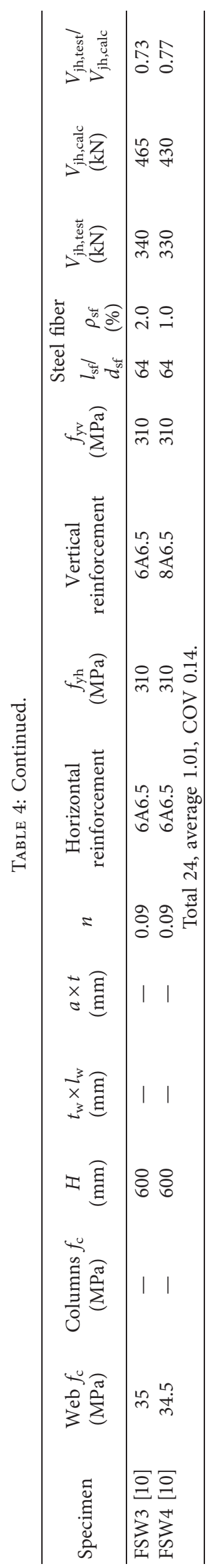




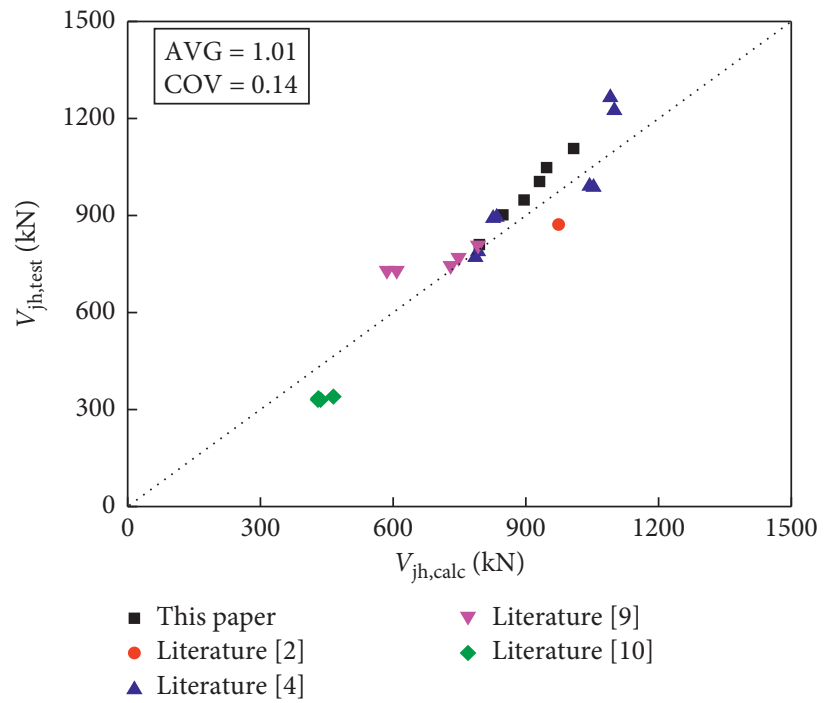

Figure 11: Correlation of experimental and predicted wall shear strengths.
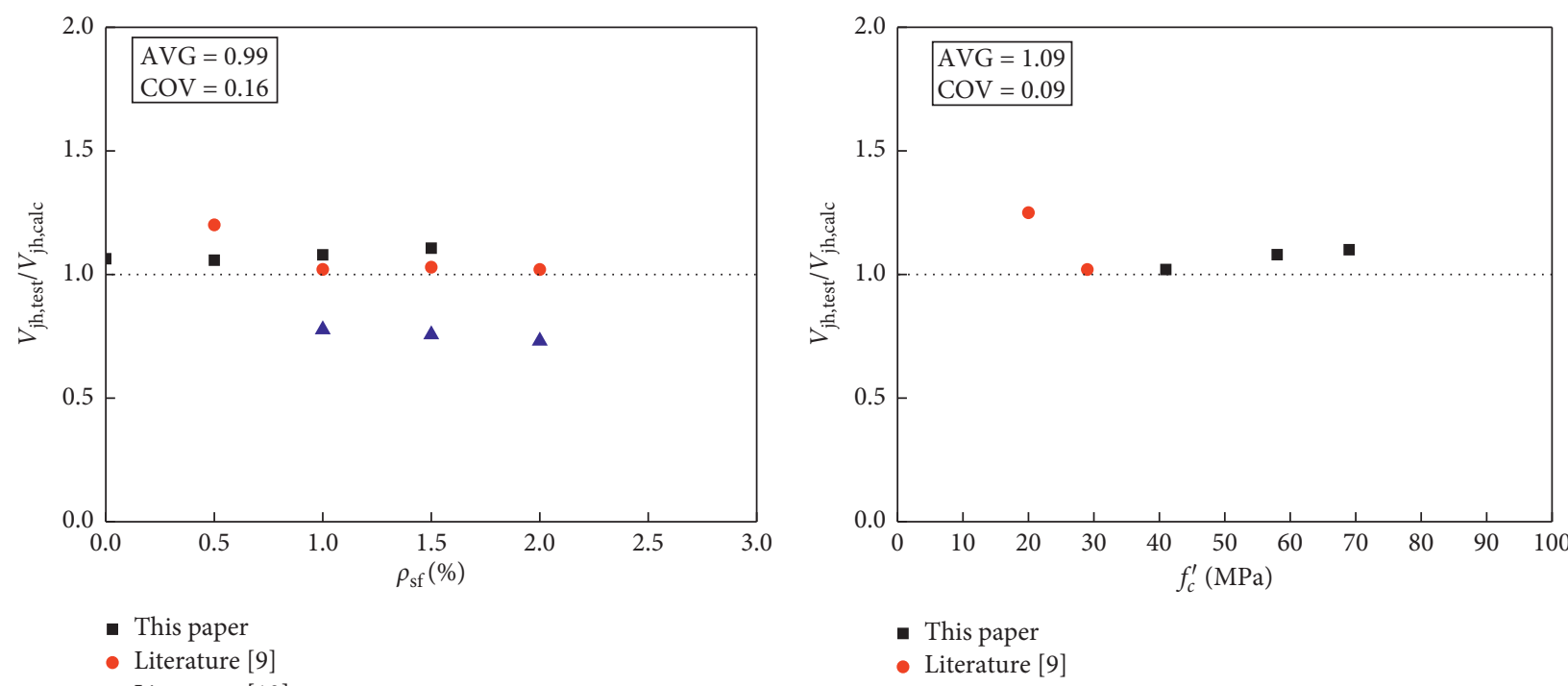

- Literature [9]

\ Literature $[10]$

- Literature [9]

(a)

(b)

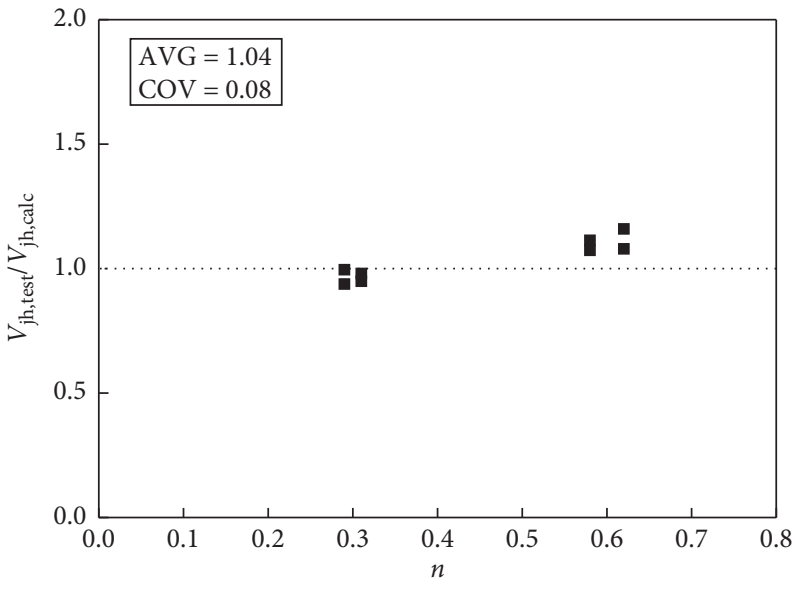

- Literature $[4]$

(c)

FIGURE 12: Effects on shear strength predictions. (a) Effect of steel fiber volume fraction on shear strength predictions. (b) Effect of concrete strength on shear strength predictions. (c) Effect of axial compression ratio on shear strength predictions. 
average principal strain in the r-direction $\varepsilon_{\mathrm{r}}$ is calculated with the aid of the compatibility equation. Then, a new value of $\zeta$ is calculated by using the softening theoretical formula. If the assumed $\zeta$ value is close to the new $\zeta$, the $V_{\text {jh }}$ selected is the shear strength of the web, otherwise back to the iterations.

Furthermore, the procedure in Figure 9 is categorized into five types according to varied yielding conditions of the ties $[15,19]$, as shown in Table 3 . Figure 10 presents the force redistribution of the web shears after the yielding of the horizontal tie.

\section{Experimental Verification}

Although the experimental design parameters of SFRC shear wall specimens, RC shear wall with CFST columns specimens, and SFRC shear wall with CFST columns specimens were different, the failure processes of shear wall specimens in this paper and the literature $[2,4,9,10]$ are similar. Based on the experimental results, the failure process generally could be divided into four stages: initial cracking stage, main diagonal cracks forming stage, limit stage, and failure stage. The web of shear wall was separated into a series of diagonal compression rhombic blocks by the intercrossing inclined cracks under gradually increasing lateral load. As the lateral load increased continuously, the concrete rhombic blocks reached ultimate compressive strength and the concrete in the web was crushed and spalled, resulting in obvious shear-dominant failure mode for the shear wall specimens in this paper and the literature $[2,4,9,10]$. The existence of steel tubes and steel fibers cannot change the ultimate failure mode of shear wall specimens. Therefore, the model presented in this paper can be used to calculate the shear strength of the abovementioned three types of shear walls failing in diagonal compressions in theory.

A total of 24 test specimens $[2,4,9,10]$ and their results (Table 4) are used to verify the proposed method, including 6 SFRC shear wall with CFST columns specimens in this paper, 9 RC shear wall with CFST columns specimens, and 9 SFRC shear wall specimens in the available literature $[2,4,9,10]$. The test specimens selected cover a wide range of structure forms, geometry, loading, steel tube, steel fiber, and reinforcement detailing, as summarized in Table 4 . The test specimens considered herein have three major common features: (1) all walls showed a web shear-dominant failure mode; (2) they were one-story isolated walls; (3) all contained both horizontal and vertical reinforcement uniformly distributed basically throughout the web.

In Figure 11, the experimental shear strengths from 24 walls are compared to their shear strengths predicted by the method presented in this paper. The relationship between the prismatic strength $f_{\mathrm{c}}$ and the cylinder strength $f_{\mathrm{c}}^{\prime}$ is obtained from literature [32]. The last column of Table 4 lists the values of $V_{\text {jh,test }} / V_{\text {jh,calc }}$ ratios to indicate the precision of the proposed model. Figure 11 shows satisfactory results for the comparison of the measured and predicted strengths. The average strength ratio $\left(V_{\text {jh,test }} / V_{\text {jh,calc }}\right)$ is 1.01 with a coefficient of variation (COV) of 0.14 (Table 4). It is concluded that the proposed model can accurately predict the shear strengths of the shear walls mentioned above.

Figure 12 shows the effects of steel fiber volume fraction, concrete strength, and axial compression ratio on the shear strength predictions of the proposed method. The steel fiber volume fraction, concrete strength, and axial compression ratio are not observed to have significant influences on the strength ratio $\left(V_{\text {jh,test }} / V_{\text {jh,calc }}\right)$, indicating that the main factors which affect the shear wall bearing capacity are reflected in the proposed model.

\section{Conclusions}

This paper introduces the tests for an innovative composite shear wall named SFRC shear wall with CFST columns and presents a proposal for determining the shear strength of the shear wall. The proposed SSTM is derived from the concept of struts and ties and satisfies equilibrium, compatibility, and constitutive laws of cracked SFRC. Based on the test results in this paper and available literature and their comparison with the proposed model, the following conclusions can be drawn:

(1) All the SFRC shear wall with CFST columns specimens showed a shear-dominant failure mode in the current tests, and all specimens mainly exhibited a typical diagonal cracking pattern during the testing process. Steel fiber could effectively control the crack width and improve the distribution shape of cracks in the web of shear wall.

(2) The shear mechanism of SFRC shear wall with CFST columns can be described by the SSTM, which consists of diagonal, horizontal, and vertical mechanisms.

(3) The steel fibers distributed randomly in concrete can be treated as longitudinal and transverse reinforcement in the shear strength analysis of SFRC shear wall with CFST columns. And the contribution of steel fiber to the wall shear strength is identified.

(4) Examination of existing experimental data indicated that the proposed model is capable of predicting the shear strengths of SFRC shear wall with CFST columns, RC shear wall with CFST columns, and SFRC shear walls for diagonal compression failures.

\section{Data Availability}

The data used to support the findings of this study are available from the corresponding author upon request.

\section{Conflicts of Interest}

The authors declare that there are no conflicts of interest regarding the publication of this paper.

\section{Acknowledgments}

The authors wish to thank Mr. Ji-Yu Tang of Zhengzhou University and Mr. Hong-Bo Han of Jinan DOCER Test 
Machine Technology Co., Ltd. for their assistance in the test programme. The research reported in the paper is part of the Project 51708514 supported by the National Natural Science Foundation of China and Key Scientific Research Projects of Colleges and Universities of Henan Provincial Department of Education (19A560005). Their financial support is highly appreciated.

\section{References}

[1] H.-S. Hu, J.-G. Nie, J.-S. Fan, M.-X. Tao, Y.-H. Wang, and S.-Y. Li, "Seismic behavior of CFST-enhanced steel platereinforced concrete shear walls," Journal of Constructional Steel Research, vol. 119, pp. 176-189, 2016.

[2] Y. Yang and W. Cao, "Seismic performance of shear wall with CFST columns and encased steel truss," Journal of Asian Architecture and Building Engineering, vol. 15, no. 3, pp. 613-618, 2016.

[3] L.-H. Han, W. Li, and Y.-F. Yang, "Seismic behaviour of concrete-filled steel tubular frame to RC shear wall high-rise mixed structures," Journal of Constructional Steel Research, vol. 65, no. 5, pp. 1249-1260, 2009.

[4] F.-Y. Liao, L.-H. Han, and Z. Tao, "Seismic behaviour of circular CFST columns and RC shear wall mixed structures: Experiments," Journal of Constructional Steel Research, vol. 65, no. 8-9, pp. 1582-1596, 2009.

[5] P. Zhang, S. Han, S. Ng, and X.-H. Wang, "Fiber-reinforced concrete with application in civil engineering," Advances in Civil Engineering, vol. 2018, Article ID 1698905, 4 pages, 2018.

[6] J. Zhao and H. Dun, "A restoring force model for steel fiber reinforced concrete shear walls," Engineering Structures, vol. 75, pp. 469-476, 2014.

[7] T. Dun, S. Kang, and O. Kim, "Earthquake resistance of structural walls confined by conventional tie hoops and steel fiber reinforced concrete," Earthquakes and Structures, vol. 7, no. 5, pp. 843-859, 2014.

[8] W. G. Lim, S. W. Kang, and H. D. Yun, "Shear behavior of squat steel fiber reinforced concrete (SFRC) shear walls with vertical slits," Applied Mechanics and Materials, vol. 372, pp. 207-210, 2013.

[9] J. Zhao, D. Y. Gao, and X. L. Du, "Seismic behavior of steel fiber reinforced concrete low-rise shear wall," Journal of Earthquake Engineering and Engineering Vibration, vol. 29, no. 4, pp. 103-108, 2009.

[10] X. R. Tang, Y. S. Jiang, and D. J. Ding, "Application of the theory of softened truss to low-rise steel fiber high strength concrete shear walls," Journal of Building Structures, vol. 14, no. 2, pp. 2-11, 1993.

[11] P. Zhang, Y.-n. Zhao, C.-h. Liu, P. Wang, and T.-h. Zhang, "Combined effect of nano- $\mathrm{SiO}_{2}$ particles and steel fibers on flexural properties of concrete composite containing fly ash," Science and Engineering of Composite Materials, vol. 21, no. 4, pp. 597-605, 2014.

[12] D. Gao, L. Zhang, J. Zhao, and P. You, "Durability of steel fibre-reinforced recycled coarse aggregate concrete," Construction and Building Materials, vol. 232, Article ID 117119, 2020.

[13] P. Zhang, Q. F. Li, Y. Z. Chen, Y. Shi, and Y. F. Ling, "Durability of steel fiber-reinforced concrete containing $\mathrm{SiO}_{2}$ nano-particles," Materials, vol. 12, no. 13, pp. 1-18, 2019.

[14] S.-J. Hwang and H.-J. Lee, "Strength prediction for discontinuity regions by softened strut-and-tie model," Journal of Structural Engineering, vol. 128, no. 12, pp. 1519-1526, 2002.
[15] S.-J. Hwang, W.-H. Fang, H.-J. Lee, and H.-W. Yu, "Analytical model for predicting shear strengthof squat walls," Journal of Structural Engineering, vol. 127, no. 1, pp. 43-50, 2001.

[16] S. J. Hwang, W. Y. Lu, and H. J. Lee, "Shear strength prediction for deep beams," ACI Structural Journal, vol. 97, no. 3, pp. 367-376, 2000.

[17] S. J. Hwang, W. Y. Lu, and H. J. Lee, "Shear strength prediction for reinforced concrete corbels," ACI Structural Journal, vol. 97, no. 4, pp. 543-552, 2000.

[18] S. J. Hwang and H. J. Lee, "Analytical model for predicting shear strengths of interior reinforced concrete beam-column joints for seismic resistance," ACI Structural Journal, vol. 97, no. 1, pp. 35-44, 2000.

[19] S. J. Hwang and H. J. Lee, "Analytical model for predicting shear strengths of exterior reinforced concrete beam-column joints for seismic resistance," ACI Structural Journal, vol. 96, no. 5, pp. 846-857, 1999.

[20] Y. Okahashi and C. P. Pantelides, "Strut-and-tie model for interior RC beam-column joints with substandard details retrofitted with CFRP jackets," Composite Structures, vol. 165, pp. 1-8, 2017.

[21] D. Y. Gao, K. Shi, and S. B. Zhao, "Calculation method for shear capacity of steel fiber reinforced concrete beam-column joints based on softened strut-and-tie model," Journal of Building Structures, vol. 47, no. 9, pp. 101-109, 2014.

[22] X. W. Liang, J. L. Che, P. H. Yang et al., "Seismic behavior of high-strength concrete structural walls with edge columns," ACI Structural Journal, vol. 110, no. 6, pp. 953-963, 2013.

[23] S. Sasmal and K. Ramanjaneyulu, "Evaluation of strength hierarchy of beam-column joints of existing RC structures under seismic type loading," Journal of Earthquake Engineering, vol. 16, no. 6, pp. 897-915, 2012.

[24] W.-Y. Lu, "Shear strength prediction for steel reinforced concrete deep beams," Journal of Constructional Steel Research, vol. 62, no. 10, pp. 933-942, 2006.

[25] M.-G. Vetr, N. Mohamad Shirali, and A. Ghamari, "Seismic resistance of hybrid shear wall (HSW) systems," Journal of Constructional Steel Research, vol. 116, pp. 247-270, 2016.

[26] S. A. Al-Ta and N. S. H. Al-Husaini, "Softened truss model theory for the analysis of fibre reinforced concrete deep beams and corbels-E," AL-Rafdain Engineering Journal (AREJ), vol. 22, no. 4, pp. 12-23, 2014.

[27] K. Schäfer, "Strut-and-tie models for the design of structural concrete," Notes of Workshop, Department of Civil Engineering, National Cheng Kung University, Tainan, Taiwan, 1996.

[28] L.-X. B. Zhang and T. T. C. Hsu, "Behavior and analysis of $100 \mathrm{MPa}$ concrete membrane elements," Journal of Structural Engineering, vol. 124, no. 1, pp. 24-34, 1998.

[29] S. J. Foster and R. I. Gilbert, "The design of nonflexural members with normal and high-strength concrete," $A C I$ Structural Journal, vol. 93, no. 1, pp. 3-10, 1996.

[30] J. Y. L. Voo and S. J. Foster, Variable Engagement Model for Fibre Reinforced Concrete in Tension, The University of New South Wales, Sydney, Australia, 2003.

[31] T. T. C. Hsu, Unified Theory of Reinforced Concrete, CRC Press, Boca Raton, FL, USA, 1993.

[32] P. Zhang, S. Fu, K. Zhang, and T. Zhang, "Mechanical properties of polyvinyl alcohol fiber-reinforced concrete composite containing fly ash and nano- $\mathrm{SiO}_{2}$," Science of Advanced Materials, vol. 10, no. 6, pp. 769-778, 2018. 